\title{
Statistical Analysis and Empirical Study for Life Insurance
}

\author{
Xiang Jiang, Jian Ni \\ Guangxi Medical and Pharmaceutical College, Nanning 530021, China \\ Tel: 86-771-2853-644Ｅ-mail: gxjxk@126.com \\ Weiqi $\mathrm{Wu}$ \\ Guangxi Industrial Vocational Technical College, Nanning 530001, China
}

Tel: 86-771-3851-662_E-mail: gxwuweiqi@163.com

\begin{abstract}
According to the uncertainty of insurance accident, in this article, we introduce the importance of insurance and the application of probability statistics in the insurance, briefly describe several parameter models about life distribution (i.e. life models), discuses the establishment and use of the life table, and statistically analyze the profit and loss and insured amount in life insurance. The result could possess certain directional meanings and reference function for practical works.
\end{abstract}

Keywords: Life insurance, Probability statistics, Statistical analysis, Life model, Empirical Study

\section{Introduction}

The probability statistics is applied abroad to insurance, including accrual and discount, survival model and life table, statistical analysis of survival and death insurance and statistical analysis of premium and compensation.

Insurance is a bargain which related to right and obligation between insurer and insurance applicant. This bargain regulates in general that the insurance applicant must pay the insurer certain amount premium, and the insurer promise to pay the insured amount when the conventional insurance accident occurs. The insurance categories are quite abundance, because of the different standards, insurance can divides into property insurance, liability insurance and life insurance. The first and second insurance are called non-life insurance, the third is called life insurance.

The calculation of life insurance premium is a complicated question. Firstly, the compositions of premium are determined by many factors. The insurance amount used to pay for the premium simply is called natural premium. But the insurer adopts from insurance applicant is not only the natural premium, but also various fees that each operation produces and various possible risks. Moreover, as the main body of economic, the venture insurance agent should consider certain profits. All those composes gross premium. The gross premium can be calculated based on natural premium. That is, calculates the natural premium according to the equivalence equation firstly, and then adds the necessary risks, fees, profits and other factors. And the calculation of gross premium can also be calculated by using the equivalence equation based on the conservative fees interest rate and weighted coefficient of death rate.

The distinct characteristic of insurance is the uncertainty happening of the insurance accident, such as people's life, traffic accident and contretemps. This characteristic also determines the important role of probability statistics in insurance categories setting, insurance operation expanding and other aspects. So, if you want to be an enviable actuary, you must be on top of statistics.

\section{Survival model}

Among the categories of insurance, life insurance is a traditional and also important insurance. Life insurance relates to people's life characteristic, therefore, it is necessary to research people's characteristic and survival model.

\subsection{Remaining Lifetime}

Supposing $T(x)$ is the insurer's remaining lifetime, apparently, it is a non-negative continuous random variable. Marking the $f_{x}(t)$ is the distribution density function of $T(x)$, and its distribution function is $F_{x}(t)=P\{T(x) \leq t\}=\int_{0}^{t} f_{x}(t) d t$. By all appearances, when $\mathrm{x}=0, T(0)$ denotes the remaining lifetime of neonatal infant, and $F_{0}(t)$ denotes the distribution function of neonatal infant's remaining lifetime.

\subsection{Common marks}

At present, international actuarial science uses the traditional mark (Zhang, 2003, P.139-183), where ${ }_{t} q_{x}$ denotes the 
probability of $x$ yeas old life's death rate in t years, ${ }_{t} p_{x}$ denotes the probability of $x$ yeas old life's survival until $t$ years later, ${ }_{s \mid t} q_{x}$ denotes the probability of the $x$ yeas old life's survival in $x+s$ years and death rate in $t$ years after that, ${ }_{t} p_{x+s}$ denotes the $x$ yeas old life's condition probability of the death rate on the condition of its $x+s$ age. And then, there are

(1) ${ }_{t} q_{x}=F_{x}(t),{ }_{t} p_{x}=1-F_{x}(t)$,

(2) ${ }_{s \mid t} q_{x}=\mathrm{P}\{\mathrm{s}$ 互 $\mathrm{T}(\mathrm{x}) \leq s+t\}={ }_{s+t} q_{x}-{ }_{s} q_{x}$,

(3) ${ }_{\mathrm{t}} p_{\mathrm{x}+\mathrm{s}}=\mathrm{P}\{\mathrm{T}(\mathrm{x})>s+t \mid T(x)>s\}=\frac{1-\mathrm{F}_{\mathrm{x}}(s+t)}{1-F_{x}(s)}$,

(4) ${ }_{\mathrm{t}} \mathrm{q}_{\mathrm{x}+\mathrm{s}}=\mathrm{P}\{\mathrm{T}(\mathrm{x}) \leq s+t \mid T(x)>s\}=\frac{\mathrm{F}_{\mathrm{x}}(s+t)-\mathrm{F}_{\mathrm{x}}(s)}{1-F_{x}(s)}$,

If $t=1, t$ always is omitted, shortening as $q_{x}, p_{x}$ and $q_{s \mid}$, etc.

\subsection{Expectation of Remaining lifetime}

If supposing $e_{x}$ is the expectation of insurant's remaining lifetime when he is $x$ yeas old, then it can be easily proved, $e^{0} e_{x}=\int_{0}^{\infty} t f_{x}(t) d t=\int_{0}^{\infty}\left(1-F_{x}(t) d t=\int_{0}^{\infty}{ }_{t} p_{x} d t\right.$

\subsection{Death intensity}

Define the $x$ yeas old life's death intensity (Zhang, 2003, P.139-183) as $\mu_{\mathrm{x}+\mathrm{t}}=\frac{\mathrm{f}_{\mathrm{x}}(t)}{1-F_{x}(t)}=-\frac{d}{d t} \ln \left(1-F_{x}(\mathrm{t})\right)$. We can see that, the death probability of $x$ yeas old life in the section of $(t, t+d t)$ can be expressed as follows,

$\mathrm{P}\{\mathrm{t}$ 庑 $\mathrm{T}(\mathrm{x}) \leq t+d t\}={ }_{t} p_{x} \mu_{x+t} d_{t}$. Therefore, the expectation of $x$ yeas old life's remaining lifetime can also calculates like ${ }_{e}^{0}=\int_{0}^{\infty} t_{t} p_{x} \mu_{x+t} d t$.

The death intensity can also be defined as $\mu_{\mathrm{x}+\mathrm{t}}=-\frac{d}{d t} \ln _{t} p_{x}$, implement the integral of this formula, we can get that ${ }_{t} p_{x}=\exp \left\{-\int_{0}^{t} \mu_{x+s} d s\right\}$. It is obvious that the death intensity of $x$ yeas old life's remaining time and the distribution function of it are defined exclusively by each other.

\section{Several parameter models about life distribution}

\subsection{Life model of De Moivre (1724)}

Life model of De Moivre considers that there is a maximal age $\omega$, and the remaining lifetime $T(x)$ of $x$ yeas old life in the section of $(0, \omega-x)$ obeys the equality distribution, i.e. $f_{x}(t)=\frac{1}{\omega-x}, 0<t<\omega-x$, so we can get the distribution function $F_{x}(t)=\frac{t}{\omega-x}, 0<t<\omega-x$, and the death intensity is $\mu_{x+t}=\frac{1}{\omega-x-t}, 0<t<\omega-x$.

\subsection{Life model of Gompertz (1825) (Zou, 2005)}

This model considers that the death intensity increasing is exponential increase, that is, $\mu_{x+t}=B C^{\mathrm{x}+t}, t>0, B>0, C>1$. By comparing with Life model of De Moivre, life model of Gompertz reflects the course of life preferably, and throws off the maximum age assumption. The calculation becomes easy. The distribution function of life model of Gompertz is $F_{x}(t)=1-\exp \left\{-\frac{B}{\ln C} e^{x}\left(C^{t}-1\right)\right\}$. In 1860, Makeham extended the model of Gompertz. He supposed that the death intensity was $\mu_{x+t}=A+B C^{\mathrm{x}+t}, t>0, A>0, B>0, C>1$, and then the distribution function was $F_{x}(t)=1-\exp \left\{-A t-\frac{B}{\ln C} e^{x}\left(C^{t}-1\right)\right\}$. If $c=1$, the death intensity of Gompertz's and Makeham's life model are constant. Then the distribution function of $T(x)$ is exponential distribution function. Although it is simple with math, it can not reflect the life-span of people.

\subsection{Life model of Weibull (Zou, 2005)}

In 1939, Weibull put forward that the death intensity of people was not exponential increase, but increase with power $t$, 
that is $\mu_{x+t}=K(x+t)^{n}, K>0, n>0$. And the distribution function of it is $F_{x}(t)=1-\exp \left\{-\frac{K}{n+1}\left[(x+t)^{n+1}-x^{n}\right]\right\}$. The above-mentioned life model is very helpful.

\subsection{Application instance of life model}

Example 1: Supposed that the death of people aggregate obeys the model of Makeham, we get the data, $\mu_{20}=0.003, \mu_{30}=0.004, \mu_{40}=0.006$, then calculate to get $_{10} q_{10}$.

Solution, According to the model of death and the known data, establish the following system of equations,

$\left\{\begin{array}{l}\mu_{20}=A+B C^{20}=0.003, \\ \mu_{30}=A+B C^{30}=0.004, \\ \mu_{40}=A+B C^{40}=0.006,\end{array}\right.$

Solving the above system of equations, we can get $A=0.002, B=0.00025, C=2^{\frac{1}{10}}$, and then the death intensity is $\quad \mu_{x+t}=0.002+0.00025 \cdot 2^{\frac{x+t}{10}}$, then $F_{x}(t)=1-\exp \left\{-0.002 t-\frac{0.00025}{\ln 2^{\frac{1}{10}}} e^{x}\left(2^{\frac{1}{10}}-1\right)\right\}$,what follows next is ${ }_{10} \mathrm{q}_{10}=\mathrm{F}_{10}(10)=1-\exp \left\{-0.002 \cdot 10-\frac{0.00025}{\ln 2^{\frac{1}{10}}} e^{10}\left(2^{\frac{10}{10}}-1\right)\right\}=0.0268^{\circ}$

\subsection{Integral remaining lifetime}

Definition $K(x)=[T(x)]$ is integral years which $x$ yeas old people will live through, sometimes called remaining lifetime. The probability distribution of integral random variable is $p\{k(x)=k\}=\mathrm{P}\{\mathrm{k} \leq T(x)$ 废 $k+1\}={ }_{k} p_{x} q_{x+k},(k=0,1,2, \Lambda$,$) . The expectation of K(x)$ is called the $x$ yeas old people's expect integral remaining lifetime, sign as $e_{x}$. Then $e_{x}=\sum_{k=1}^{\infty} k P\{K(x)=k\}=\sum_{k=1}^{\infty} k{ }_{k} p_{x} \cdot q_{x+k}$, or $e_{x}=\sum_{k=1}^{\infty} P\{K(x) \geq k\}=\sum_{k=1}^{\infty}{ }_{k} p_{x}$.

The advantage of using the integral remaining lifetime of $x$ yeas old people is that it predigests the remaining lifetime of $x$ yeas old people, and it is convenient to the calculation of expectation of remaining lifetime.

Making $S(x)=T(x)-K(x), S(x)$ is the fraction part of the years which $x$ yeas old people has lived. It is easy to see that $S(x)$ is a continuous random variable on the integral of $(0,1)$. Assuming that $K(x)$ and $S(x)$ are independent, then the conditional distribution of $S(x)$ do not depend on $K(x)$ when the value of $K(x)$ is given, and $P\{S(\mathrm{x}) \leq u \mid K(x)=k\}=\frac{{ }_{u} q_{x+k}}{q_{x+k}}$.

Presupposes above formula equal to $H(u), H(u)$ is a certain function which has nothing to do with $k$. There with, ${ }_{u} q_{x+k}=H(k) q_{x+k}, k=1,2, \Lambda$. Supposing $H(u)=u$, that is,$S(x)$ is a homogeneous distribution in the integral of $(0,1)$, then $e_{x}^{0}=e_{x}+\frac{1}{2}, \operatorname{Var}(T(x))=\operatorname{Var}(K(x))+\frac{1}{12}$.

Because that the distribution of $K(x)$ all depends on $q_{x}$, therefore, can structure all kinds of table by means of $q_{x}$. The common life table of insurance is table of $q_{x}$.

\section{The composition and application of life table}

Through the research on the distribution function of life, that is a random variable, the probability density function and expectation, the probability of certain people's death in certain time or in instantaneous can be expressed as survivorship function and some special symbols. That is to say, we can estimate the life state of insurant in optional age. In practice, we often use the life to stand for this. The survivorship function and life table are connected with each other, and the survivorship function can be calculated through life table. Life table are summary table which be established according to the statistic data of each age's death in certain time.

\subsection{Aufbau principle of life table}

On the basis of principle of larger number, the survival probability of each age people can be calculated by observed data (estimating frequency by frequency). The common symbols include, new-born life number is $l_{0}$, $\mathrm{x}$ is the age, and $\omega$ is the utmost age. 


\subsection{Characteristics of life table}

The Aufbau principle of life table is simple, and is not determined by the total distribution (non-parameter method). The survival expectation number of $l_{0}$ new-born life will live to age $\mathrm{X}$ is $l_{\mathrm{x}}=l_{0} \cdot \mathrm{s}(\mathrm{x})$, the death expectation number of $l_{0}$ new-born life will die between the age of $\mathrm{x}$ and $\mathrm{x}+\mathrm{n}$ is ${ }_{0} d_{\mathrm{s}}$. Especially, when $\mathrm{n}=1$, mark as ${ }_{\mathrm{n}} d_{\mathrm{x}}=l_{\mathrm{x}}-l_{\mathrm{x}+\mathrm{n}}=l_{\mathrm{x}}{ }_{\mathrm{n}} q_{\mathrm{x}}, d_{\mathrm{x}}=l_{\mathrm{x}}$

$-l_{\mathrm{x}+1}=l_{\mathrm{x}} \cdot q_{\mathrm{x}}$. The sum of years which $l_{0}$ new-born life live through on the integral of $\mathrm{x}$ and $\mathrm{x}+\mathrm{n}$ is ${ }_{\mathrm{x}} L_{\mathrm{x}}=\int_{\mathrm{x}} l_{y} d y$, and the total number of the individual's remaining life, which can live to age $\mathrm{x}$, is $T_{\mathrm{x}}=\int_{x}^{\infty} l_{y} d y$, then can get $e_{x}^{n}=\frac{T_{x}}{l_{x}}$.

\subsection{Application instance of life table}

Example 2: The known value is $l_{x}=10000\left(1-\frac{x}{100}\right)$, please calculate the following values, (1) $d_{30,20} p_{30,30} q_{30,10} \mid q_{30}$, (2) the death probability of 20 years old people in the integral of 50 to 55 , (3) the average life of the people.

Solution: (1) $\mathrm{d}_{30}=\mathrm{l}_{30}-\mathrm{l}_{31}=100,{ }_{20} \mathrm{p}_{30}=\frac{l_{50}}{l_{30}}=5 / 7$,

${ }_{30} \mathrm{q}_{30}=\frac{l_{30}-l_{60}}{l_{30}}=3 / 7 \quad{ }_{10} \mathrm{q}_{30}=\frac{l_{40}-l_{41}}{l_{30}}=1 / 70$,

(2) ${ }_{30 \mid 5} \mathrm{q}_{20}=\frac{l_{50}-l_{55}}{l_{50}}=1 / 16$,

(3) $e_{x}^{n}=\frac{T_{x}}{l_{x}}=\int_{i}^{\infty}\left(1-\frac{x}{100}\right) d x=50$

4.4 Aufbau principle of selection-ultimate life table (as seen in Table 1)

The health of new employees which get through the fresh physical examination excels the health of old employees which got through the physical examination at a long time ago. The force of selection will disappear with time.

\subsection{The application of selection-ultimate life table}

The application of life table and the result of calculation expresses as the table 2.

\subsection{The assumption about fraction age}

4.6.1 Survival situation in life table

Using background, life table provide the distribution of integral age, but sometime we need to analysis the survival situation, so we select the distribution of certain age based on the two data border upon, and estimate the survival situation of fraction age.

4.6.2 Basic principles and common method (interpolation method)

Basic principles and common method (interpolation method) include

(1) Assumption of the equality distribution (linear interpolation), $\mathrm{s}(\mathrm{x}+\mathrm{t})=(1-\mathrm{t}) \mathrm{s}(\mathrm{x})+\mathrm{ts}(\mathrm{x}+1), 0<\mathrm{t}<1$,

(2) Assumption of the death force (geometrical interpolation), $\mathrm{s}(\mathrm{x}+\mathrm{t})=\mathrm{s}(\mathrm{x})^{(1-\mathrm{t})} \cdot \mathrm{s}(\mathrm{x}+1)^{\prime}, 0<\mathrm{t}<1$,

(3) Assumption of Balduccl (harmonious interpolation), $\frac{1}{s(x+t)}=\frac{1-t}{s(x)}+\frac{t}{s(x+1)}, 0<t<1$.

Example 3: The known value is $l_{x}=10000\left(1-\frac{x}{100}\right)$, please calculate the following values under three different fraction age, $0.5 \mathrm{q}_{30,5.25} \mathrm{q}_{50}, \mu_{30.5}$.

Solution, under the three assumptions,

(1) Because $q_{30}=\frac{l_{30}-l_{31}}{l_{30}}=\frac{1}{70}$, so, $e^{-n}=p_{30}=\frac{69}{70}$,

${ }_{0.5} \mathrm{q}_{30} \underline{\underline{U D D}}{ }^{0.5 \mathrm{q}_{30}=} \frac{1}{140}$,

${ }_{0.5} \mathrm{q}_{30} \underline{\underline{C F}} 1-\mathrm{e}^{30}={ }_{1-\sqrt{\frac{69}{70}}}$, 
${ }_{0.5}^{0} \mathrm{q}_{30} \underline{\underline{\text { Balducci }}} \frac{0.5 q_{30}}{\mathrm{p}_{30}+0.5 q_{30}}=\frac{1}{139}$.

(2) ${ }_{5.25} \mathrm{q}_{50}={ }_{5} \mathrm{q}_{30}+{ }_{5} \mathrm{p}_{50}{ }_{0.25} \mathrm{q}_{55}$,

Because ${ }_{5} \mathrm{q}_{50}=0.1,{ }_{5} \mathrm{p}_{50}=0.9, \mathrm{q}_{55}=\frac{1}{45}$

so, ${ }_{5.25} \mathrm{q}_{50} \underline{\underline{U D D}}{ }^{0.1+0.9 \cdot 0.256} \frac{1}{\frac{15}{45}}=0.105$,

${ }_{5.25} \mathrm{q}_{50} \underline{\underline{C F}} 0.1+0.9 \cdot\left(1-\frac{44^{0.25}}{45}\right)=0.1050422$,

${ }_{5.25} \mathrm{q}_{50} \underline{\underline{\text { Balducci }}} 0.1+0.9 \frac{0.25}{44+0.25}=0.1050847$.

(3) $\mu_{30.5} \underline{\underline{U D D}} \frac{q_{30}}{1-0.5 q_{30}}=\frac{1}{69.5}$,

$\mu_{30.5} \underline{\underline{C F}} \mu=-\ln \left(\mathrm{p}_{30}\right)=-\ln \frac{69}{70}$,

$\mu_{30.5} \underline{\underline{\text { Balducci }}} \frac{q_{30}}{\mathrm{p}_{30}+0.5 q_{30}}=\frac{1}{69.5}$.

\section{The insurance profit and loss analysis based on central limit theorem}

\subsection{The central limit theorem and its meaning}

The central limit theorem points out that if one random variable is induced by numerous random factors, and every successive change has few functions, so it could deduce that the random variable which describes the random phenomena obeys the normal school. So to require the sum of random variables in certain area, we should only standardize it and approximately computes it by the normal school. The central limit theorem has directional meaning for the insurance industry, and through it, we can estimate and predict the profit and loss of one insurance company, and the law of larger numbers is the based to establish the modern insurance industry. The following example expatiates on the important function and concrete application of the law of larger numbers and the central limit theorem in the insurance industry.

\subsection{Example analysis and solution}

Example 4: Suppose that there are 10000 people take part in the insurance in one insurance company, and every one pays premium of 12 Yuan to the company every year, and everyone's death probability in one year is 0.006 , and his family numbers could draw 1000 Yuan from the insurance company when he dies, then answer the questions, (1) how big the loss probability of the insurance company is? , and (2) how big the probability that the profit of the insurance company in one year is not less than 4000 Yuan?

Solution, Supposing that the number of the death in 10000 people in one year is $X$, so $X \sim B(n, p), n=10^{4}, p=0.006$, $q=1-p$, and the year income of the insurance company is $12 \times 10000-1000 X$.

(1) If the insurance company loses money in business, so $12 \times 10000-1000 X<0$, and $X>120$. From the central limit theorem, $P\{x>120\}=P\left\{\frac{X-n p}{\sqrt{n p q}}>\frac{120-n p}{\sqrt{n p q}}\right\}=1-\Phi\left(\frac{120-10000 \times 0.006}{\sqrt{10000 \times 0.006 \times 0.994}}\right)=1-\Phi(7.76931) \approx 0$.

So the insurance company would not loss money in business.

(2) If the year profit of the insurance company is not less than 40000 Yuan, so $12 \times 10000-1000 X \geq 40000$ and $X \leq 80$.

$P\{x \leq 80\}=P\left\{\frac{X-n p}{\sqrt{n p q}} \leq \frac{80-n p}{\sqrt{n p q}}\right\}=\Phi\left(\frac{80-10000 \times 0.006}{\sqrt{10000 \times 0.006 \times 0.994}}\right)=\Phi(2.59) \approx 0.995$

So the probability that the year profit of the insurance company is not less than 40000 Yuan is 0.995 .

\subsection{Result analysis and discussion}

Through analysis and solution of the example, we could clearly understand why so many insurance companies come into existence, because the loss probability of insurance company almost is zero, and why insurance type is better for the insurance company in so many insurance types pushed by the insurance companies at present, and we could feel that "the probability statistics is surrounding us", and its application is very extensive. 


\section{Statistical analysis of insured amount in life insurance}

The death insurance is the insurance type taking human death as the insurance standard, and if the insurant dies in the time limit of contract, the insurer should pay insured amount to the insurant, and if the insurant live after the time limit of contract, the insurer needs not pay the insured amount. Therefore, the confirmation of insured amount depends on the time limit of contract and the probability character of insurant's reminding life, and it also should consider many factors such as the profit of insurance company, the gross income and payout.

According to different payment times of insured amount, the payment method of insured amount can be divided into two sorts, i.e. paying in the late of the year when the insurant dies, and paying when the insurant dies. First, we introduce the first sort.

Supposing that the contract regulates that after the insurant insures his life when he is $x$ years old, if he dies in the future $n$ years, the insurer should pay the insured amount of one money unit to the insurant in the year he dies, and if the insurant could live after $x+n$ years, the insurer would pay nothing. Suppose $b(k)$ denotes the insured amount paid in the $k$ 'th year, $v(k)$ denots the discount factor in the $k$ 'th year. So,

$b(k)=\left\{\begin{array}{l}1,0<K(x) \leq n, \\ 0, K(x)>n,\end{array}\right.$ and the present value of the insured amount is noted as $Z_{x, n}(K(\mathrm{x}))$, so

$Z_{x, n}(K(\mathrm{x}))=b\left(K(x) v^{k(x)}= \begin{cases}v^{k(x)}, & 0<K(x) \leq n, \\ 0, & K(x)>n .\end{cases}\right.$

The expectation and the variance of the present insured amount value respectively are

$A_{x}(n)=E\left[Z_{x, \omega}(K(x))\right]=\sum_{k=0}^{n-1} v^{k} P\{k \leq K(x)<k+1\}=\sum_{k=0}^{n-1} v^{k+1}{ }_{k} p_{x} \cdot q_{x+k}$

and $\operatorname{Var}\left[Z_{x, n}(K(x)]=E Z_{x, n}^{2}\left(K(x)-A_{x}^{2}(n)=\sum_{k=0}^{n-1}{ }_{k} p_{x} \cdot q_{x+k} v^{2(k+1)}-A_{x}^{2}(n) \cdot\right.\right.$

Note, If $\mathrm{n}$ in the above formula is equal to the limit age $\omega$, the insurance is the death insurance for life, and the present expectation value of the insured amount is $A_{X}(\omega)=E Z_{x, \omega}(K(x))=\sum_{k=0}^{\omega-x-1}{ }_{k} p_{x} \cdot q_{x+k} v^{k}$.

In the death insurance for life, the payment of the insured amount is the late of the death year, so under the hypothesis that the insured amount is one money unit and the interest is the constant, the following relationship could come into existence.

$A_{x}(\omega)=v q_{x}+v p_{x} \cdot A_{x+1}(\omega)$.

\section{Conclusions}

Empirical study indicated that through almost 20 years' development, the actuarial mathematics had gradually developed to be a professional subject from a sort of special computation method, and its application range was gradually expanding, and it had certain directional meanings and better referenced function for the practical work of insurance. Because of the length, in the article, we only introduce few most basic and simple contents about insurance, and the study and application about the integration of insurance, probability statistics and actuarial mathematics should be further discussed by us.

\section{References}

H.U.Gerber. (1999). The Mathematics of Compound Interest. Shanghai, Shanghai World Book Publishing Company. Oct., 1999. P.162-189.

Lin, Weiran. (2006). The Parameter Estimation of Death Force Function Based on Selection-Ultimate Life Table. Journal of Heifei University of Technology (Natural Science). No.6. P.972-976.

Mi, Xiaoqin. (2004). Statistics in Life Insurance Theory. Beijing Statistics. No.1.

Wangyan. (2008). Actuarial Science of Life Insurance. Beijing, China Renmin University Press. May, 2008. P.102-117.

Wei, Zongshu. (2004). Tutorial of Probability Theory and Mathematical Statistics. Beijing, Higher Education Press. Aug, 2004.

Zhang, Minyue. (2003). Study of Residual Life Function in Reliability Theory. Journal of Lanzhou University of Technology. No.5. P.139-183.

Zhou, Jiangxiong. (2006). The Constructing Theory of Life Table (2ed Edition). Tianjin, Nankai University Press. P.9-13.

Zou, Gongming. (2005). Survival Models and Their Estimation. Shanghai, Shanghai University of Finance \& 
Economics Press. 1 Aug, 2005.

Table 1. Selection-ultimate life table

\begin{tabular}{|c|c|c|c|c|c|c|}
\hline Age area & $\begin{array}{l}\text { Death } \\
\text { proportion }\end{array}$ & $\begin{array}{l}\text { Survival } \\
\text { Number at the } \\
\text { beginning of the term }\end{array}$ & $\begin{array}{l}\text { Death } \\
\text { number } \\
\text { in the term }\end{array}$ & $\begin{array}{l}\text { Survival years } \\
\text { in the age } \\
\text { area }\end{array}$ & $\begin{array}{l}\text { Sum of } \\
\text { remaining life }\end{array}$ & $\begin{array}{l}\text { Average } \\
\text { remaining } \\
\text { life at the } \\
\text { beginning } \\
\text { of the term }\end{array}$ \\
\hline$x-x+t$ & rqt & $\mathrm{xl}$ & $\mathrm{xds}$ & $\mathrm{tlx}$ & $\mathrm{Tx}$ & ex \\
\hline $0-1$ & .00463 & 100000 & 463 & 273 & 7287758 & 73.88 \\
\hline $1-7$ & .00246 & 99537 & 745 & 1635 & 7387485 & 74.22 \\
\hline $7-28$ & .00139 & 99292 & 138 & 5708 & 7385850 & 74.38 \\
\hline $0-1$ & .01260 & 10000 & 1260 & 96973 & 7387758 & 73.88 \\
\hline $1-2$ & .00093 & 98740 & 92 & 98694 & 7288785 & 73.82 \\
\hline $2-3$ & .00065 & 98648 & 64 & 98617 & 7190091 & 72.89 \\
\hline
\end{tabular}

Table 2. Use and computation of selection-ultimate life table

\begin{tabular}{|l|l|l|l|l|l|l|l|}
\hline & $\mathrm{q}[\mathrm{x}]$ & $\mathrm{q}[\mathrm{x}+1]$ & $\mathrm{q}[\mathrm{x}+2]$ & $\mathrm{q}[\mathrm{x}+3]$ & $\mathrm{q}[\mathrm{x}+4]$ & $\mathrm{q}[\mathrm{x}+5]$ & $\mathrm{x}+5$ \\
\hline 70 & .0175 & .0249 & .0313 & .0388 & .0474 & .0545 & 75 \\
\hline 71 & .0191 & .0272 & .0342 & .0424 & .0518 & .0596 & 76 \\
\hline 72 & .0209 & .0297 & .0374 & .0463 & .0566 & .0652 & 77 \\
\hline 73 & .0228 & .0324 & .0409 & .0507 & .0620 & .0714 & 78 \\
\hline 74 & .0249 & .0354 & .0447 & .0554 & .0678 & .0781 & 79 \\
\hline 75 & .0273 & .0387 & .0489 & .0607 & .0742 & .0855 & 80 \\
\hline 76 & .0298 & .0424 & .0535 & .0664 & .0812 & .0936 & 81 \\
\hline 77 & .0326 & .0464 & .0586 & .0727 & .0889 & .1024 & 82 \\
\hline
\end{tabular}

Table 3. Function comparison analysis of life table under three hypotheses

\begin{tabular}{|l|l|l|l|}
\hline function & even distribution & constant death force & Bellucci \\
\hline tqx & tqx & $1-\mathrm{e}-\mathrm{nt}$ & $\frac{t \cdot q_{t}}{1-(1-t) \cdot q_{t}}$ \\
\hline $\operatorname{tpx}$ & $1-$-tqx & e-nt & $\frac{p_{t}}{1-(1-t) \cdot q_{t}}$ \\
\hline $\mathrm{yqx}+\mathrm{t}$ & $\frac{y q_{x}}{1-t q_{x}}$ & $1-\mathrm{e}-\mathrm{nt}$ & $\frac{y \cdot q_{t}}{1-(1-y-1) \cdot q_{t}}$ \\
\hline$\mu \mathrm{x}+\mathrm{t}$ & $\frac{q_{x}}{1-t q_{x}}$ & $\mu$ & $\frac{q_{t}}{1-(1-t) \cdot q_{t}}$ \\
\hline $\mathrm{fr}(\mathrm{t})$ & $\mathrm{qx}$ & $-\mathrm{e}-\mathrm{ntu}$ & $\frac{p_{x} \cdot q_{t}}{\left[1-(1-t) \cdot q_{t}\right]^{2}}$ \\
\hline
\end{tabular}

